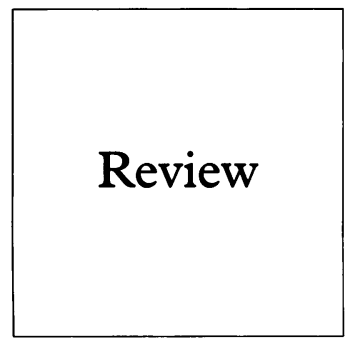

\section{Sexually transmitted diseases in mobile populations}

\author{
David Mabey, Philippe Mayaud
}

\section{Introduction}

STDs and travel: an ancient association

Sexually transmitted diseases have been associated with travel, and indeed blamed on travellers (particularly foreigners) since they were first described. The history of syphilis in Europe illustrates this well. Within two or three years of its first description in Naples, the disease had apparently spread to virtually every corner of Europe, transported presumably not only by the returning mercenary army of King Charles VIII of France, but also by camp followers, traders, sailors, pilgrims and other mobile populations. The variety of names given to the new disease reflects the perception that it was introduced by foreign travellers. The French called it the "mal de Naples", the Italians the "morbus gallicus" (French disease), the English called it the "French pox", and so on."

The study of, and clinical services for sexually transmitted diseases (STDs) were for many years the province of military and naval doctors, reflecting the high incidence of these diseases among mobile male populations; but the unique role of the armed forces in the dissemination of STDs has now been eclipsed by the extraordinary increase in international travel by civil populations in the past 50 years. Tourism is now the world's biggest industry. In 1993, UK residents made 36 million visits to foreign countries, and 19 million foreigners visited this country. Thirty million UK citizens visited Western Europe, three million North America and three million the rest of the world, including some 700000 to subSaharan Africa. ${ }^{2}$ Although the vast majority of international travellers are holiday makers, the UN High Commission for Refugees estimates that there are at least 20 million refugees in the world who have fled from their countries of origin, and the International Labour Organisation states that there are some 30 million migrant workers ${ }^{3}$; the role played by such longer-term travellers in the transmission of STDs may be disproportionately large.

The incidence and prevalence of many STDs varies greatly from one country to another, reflecting demographic, socioeconomic and cultural differences, and variation in the accessibility of effective treatment and of condoms. For example, the incidence of gonorrhoea in many European countries is now well below 100 per 100000 total population per year, whereas the incidence in certain African countries is believed to be over 5000 per $100000 .{ }^{4}$ The higher incidence and prevalence of the treatable bacterial STDs, particu-

\author{
Dr D Mabey. \\ Accepted for publication \\ 11 December 1996 \\ Sciences, London \\ Tropical Medicine, \\ D Mabey \\ P Mayaud \\ Address correspondence to:
}

larly those such as chancroid and syphilis which cause genital ulceration, probably explains why there is a heterosexual HIV/AIDS epidemic in sub-Saharan Africa but not in Western Europe. People travelling from low prevalence regions to countries o where over $10 \%$ of the adult population are $\overrightarrow{0}$ HIV positive may not be aware of the enormously increased risk of exposing themselves to infection through casual heterosexual contact.

This review will consider what is known about STDs in three mobile populations: $\vec{\infty}$ international travellers from Europe, migrant 은 workers in Southern Africa, and Rwandan refugees in camps in Tanzania; and will assess the possible options for STD control among these different categories of traveller.

Imported HIV infections in the UK

The only data currently available in the UK on imported STDs relate to HIV infection. According to the Communicable Disease Surveillance Centre, the increase in reports of heterosexually acquired AIDS and HIV infection is more rapid than the increase in any other exposure category, and more than $70 \%$ of heterosexually acquired infections are contracted abroad. ${ }^{56}$ The number of reported AIDS cases infected heterosexually rose from less than 50 in 1988 to almost 300 in 1993, and reported HIV infections in this category rose from about 200 in 1987 to over 600 in 1991.

Yet it is likely that reported cases of HIV 옥 infection among heterosexuals represent the tip of an iceberg. If people do not consider themselves at risk of HIV infection, they will of not ask for a test. The results of unlinked $N$ anonymous surveillance among heterosexual N STD and antenatal clinic attenders suggest that over $50 \%$ of infections in each category had not been diagnosed by voluntary named testing. ${ }^{7}$

We have conducted an anonymous, $\frac{T}{0}$ unlinked survey of HIV prevalence in international travellers attending the Hospital for $\stackrel{\mathbb{D}}{\mathbb{D}}$ Tropical Diseases, London. ${ }^{8}$ Of 782 subjects approached over a six month period (December 1991-May 1992), 757 agreed to 8 participate (97\%). Four hundred and fifty four were men (mean age 32 years), and 303 women (mean age 28 years). Seventy nine percent of subjects originated from WHO pattern 1 countries (ie North America, Western Europe or Australasia); $61 \%$ had spent fewer than three months abroad, but $18 \%$ had spent more than one year abroad on their most 
recent trip. One hundred and forty one subjects $(18 \cdot 6 \%)$ reported having sex with at least one new partner during their most recent trip, and $48 \%$ of these admitted to more than one new partner. The geographical origins of these 141 respondents and their 249 sexual partners are shown in the table; clearly there was considerable sexual mixing between subjects from "pattern 1" countries, where HIV is transmitted predominantly through homosexual contact and sharing of needles, and people from regions with a higher prevalence of heterosexually acquired HIV infection.

Sixteen of 731 subjects tested were positive for anti-HIV-1 antibodies $(2 \cdot 2 \%)$. Eleven of these originated from sub-Saharan Africa, 4 from the UK and one homosexual man from elsewhere. The prevalence of HIV infection among males originating from the UK was $4 / 268(1.5 \%)$ in this study; if the analysis is confined to heterosexual men, $3 / 250$ were infected $(1 \cdot 2 \%)$.

Patients attending the Hospital for Tropical Diseases are unlikely to be a representative sample of overseas travellers. The majority attend for a routine health screen after visiting a tropical region, and they may therefore be an unusually health conscious sample of such travellers. On the other hand, some may attend the hospital because of symptoms attributable to HIV infection. It is interesting to note that the HIV prevalence found in this study is similar to those found among Belgian and Dutch expatriates living in Africa. Bonneux et al found a prevalence of $1 \cdot 1 \%$ (15/1401) among Belgian advisers who had spent at least six months in Africa in the previous five years ${ }^{9}$; Houweling and Coutinho studied Dutch expatriates returning from at least six months in sub-Saharan Africa, and found a prevalence of $0.4 \%$ in men $(4 / 1122)$, and $0.1 \%$ in women $(1 / 846)$. Four of the five seropositive individuals reported African heterosexual partners, and had been treated for STDs. ${ }^{10}$

\section{Sexual behaviour of Britons abroad}

Gillies et al used a postal survey of 1030 adults aged 16-40 years selected from the register of a general practice in Nottingham to measure the prevalence of risky sexual behaviour abroad in the general population. ${ }^{11}$ Although the response rate was only $56 \%$, some interesting findings emerged. Sixty six percent (354/548) had travelled abroad in the previous 12 months, and 17 of these ( $5 \%$ ) had sex with a new partner whilst abroad. Although 12 of the 17 had carried condoms, they had not always used them, perhaps because having sex with a new partner was strongly associated with "get- ting very drunk". This is one of the few studies of sexual behaviour in travellers to have examined a population-based sample; it is therefore presumably generalisable to other UK populations.

Other studies have been conducted among genitourinary medicine (GUM) clinics attenders in the UK. Mendelson et al administered a questionnaire to 464 patients attending a clinic in Birmingham with a new complaint who had recently travelled overseas. ${ }^{12}$ Twenty eight percent admitted to sex with a new partner while abroad, and only $42 \%$ stated that they had consistently used condoms. Twenty nine percent of those admitting to sex abroad had had more than one partner. The first partner of $63 \%$ of subjects originated from outside the UK. Daniels et al administered a questionnaire to 250 attenders at two GUM clinics in London. ${ }^{13}$ Of 243 responders $81 \%$ had travelled abroad in the preceding six months. Eighteen of 90 women $(20 \%), 26 / 53$ heterosexual men (51\%) and 19/53 homosexual men (36\%) admitted to sex with a local foreign contact while on holiday.

\section{STDs in migrant workers in Southern Africa}

Rural-urban migration has increased enormously throughout the developing world in the past 50 years as a result of population pressure and environmental impoverishment. Young men travel into cities in search of employment, leaving their families behind; women are often left with no means of support other than prostitution. This pattern of migration has had a profound influence on the epidemiology of STDs, and particularly on the HIV/AIDS epidemic, in sub-Saharan Africa.

Studies in rural populations in both East and West Africa have found that individuals who travel out of their village are at increased risk of HIV infection. ${ }^{14}$ This no doubt reflects a general phenomenon of greater sexual freedom among travellers: in the survey of national sexual lifestyles in the UK, women who regularly spent nights away from home were more likely to have more than one sexual partner. ${ }^{16}$ In Cote d'Ivoire, it has been estimated that $25 \%$ of the total population, and $40 \%$ of the population of the capital city, are immigrants from neighbouring countries attracted by the possibility of paid employment. Male immigrants usually come for a limited period, and do not bring their families with them; they typically live in camps at their place of work, and obtain sex from prostitutes who may have $10-15$ partners per day. ${ }^{17}$ More than half the professional prostitutes in Abidjan are Ghanaian, and more than $80 \%$ are HIV positive.

Patterns of sexual mixing in UK recruited international travellers $(n=141)$

\begin{tabular}{|c|c|c|c|c|}
\hline \multirow[b]{2}{*}{ Country/region of birth respondent } & \multicolumn{4}{|c|}{ Country/region of birth of sexual partner } \\
\hline & Pattern 1 & Sub-Saharan Africa & Asia & Rest of world \\
\hline $\begin{array}{l}\text { Pattern } 1(n=117) \\
\text { Sub-Saharan Africa }(n=18) \\
\text { Asia }(n=3) \\
\text { Rest of world }(n=3)\end{array}$ & $\begin{array}{r}121 \\
4 \\
1 \\
2\end{array}$ & $\begin{array}{l}39 \\
16 \\
-\end{array}$ & $\begin{array}{r}33 \\
2 \\
2 \\
-\end{array}$ & $\frac{22}{1}$ \\
\hline
\end{tabular}


The institution of migrant labour has been present for much longer in Southern Africa, and is practised on a greater scale. In 1986, there were over three million male workers officially registered as migrants in South Africa. ${ }^{18}$ These workers were mostly from the "independent homelands", but more than 350000 were from other countries in southern Africa; moreover, it was estimated at the time that there were, in addition to registered workers, some 150000 unregistered work-seekers from Mozambique in South Africa. Until the recent political changes, these men were not permitted to bring their families to live with them at their place of work. Now, although it is no longer illegal, most cannot afford it, and continue to live in single-sex hostels which may house several thousand single men.

This system of migrant labour has brought handsome profits for the industries of South Africa, but has fuelled a disastrous epidemic of STDs including, in the past decade, HIV infection. In 1949 Kark observed the prevalence of syphilis in antenatal clinics in South Africa to be between 20 and $40 \% .^{19}$ Subsequent studies have confirmed the importance of congenital syphilis as a cause of perinatal mortality in South Africa. ${ }^{20}$

The incidence of STDs is remarkably high among migrant workers. Mine hospital records have documented rates as high as 30 attendances for STDs per 100 miners per year, and this is likely to be an underestimate of the true incidence since many miners prefer to seek treatment elsewhere. ${ }^{21}$ The incidence of genital ulcer disease appears to be particularly high in South Africa, where all the common causes of this syndrome are prevalent. ${ }^{22}$ This has no doubt contributed to the speed with which HIV infection has spread in the country; although no HIV prevalence data are available for mine workers since 1986, when the prevalence was $0.02 \%$ among miners of South African origin, but $3.8 \%$ in those from Malawi, ${ }^{18}$ the prevalence of HIV infection in antenatal clinic attenders in South Africa has risen from $0.8 \%$ in 1990 to $7.6 \%$ in 1994 . In Kwazulu-Natal it has risen from $1.6 \%$ to $14 \cdot 4 \%$ over the same period.

\section{STDs among Rwandan refugees in Tanzania}

Rwanda has been one of the African countries most severely affected by the HIV/AIDS epidemic. ${ }^{23}$ After the disastrous events which took place in the country between April and June 1994, more than 300000 refugees crossed the border into Tanzania within a few weeks, and were accommodated in two large camps in the Ngara District, an area with a rather low prevalence of HIV infection. ${ }^{24}$ As is usual in such an emergency situation, priority was given to the provision of shelter, food, water and medical services for the treatment of acute life-threatening conditions. The treatment of STDs was not seen as a priority.

Improved syndromic management of STDs has recently been shown to reduce the incidence of HIV infection by over $40 \%$ in the nearby Mwanza Region of Tanzania. ${ }^{25}$ If, as seemed likely, STDs were prevalent in this refugee population, high priority should be given to the provision of services for their treatment, in order to reduce the spread of HIV infection within the refugee camps and into the surrounding Tanzanian population.

Rapid assessment methods have been used ${ }_{\Omega}$ previously to prioritise health interventions in $\stackrel{1}{\triangle}$ refugee camps. ${ }^{26}$ Cluster sampling techniques, originally developed to assess vaccine coverage, have been used to assess morbidity and $\frac{5}{\zeta}$ nutritional status, but STD prevalences have not been measured in this way. The World Health Organisation (WHO) has conducted two rapid assessments of STD prevalence in? various populations in Uganda and Senegal, $\frac{\bar{O}}{\bar{N}}$ using different sampling strategies, and have $\frac{\text { क }}{\bar{\sigma}}$ helped to develop and validate STD indicators which can be used in such surveys. ${ }^{27} 28$ Wew have combined these two methodologies to $\overrightarrow{0}$ measure for the first time the prevalence of STDs in two large refugee camps in the Ngara district of Tanzania. ${ }^{29}$

This survey was conducted in August 1994, four months after the start of the Rwandan massacres. One hundred women attending $\vec{\infty}$ antenatal clinics in the camps were inter-o viewed and examined, 239 men attending out- patient (OP) clinics, and 289 men aged 15-54 T) years selected at random from the community. 을 Although $37 \%$ of men in both groups reported no sexual activity in the past three months, there was a high prevalence of STD related symptoms; $12 \%$ of male OP clinic attenders complained of dysuria, genital discharge, ulcero

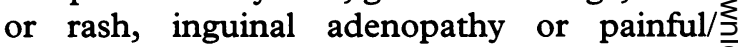
swollen scrotum, and $28 \%$ of men in the community. However, in many cases these com- $\mathbb{D}$ plaints were not substantiated on examination. $\stackrel{2}{\Rightarrow}$

A first void urine sample from male subjects was screened using a leucocyte esterase dipstick (LED). A urethral swab for Gram stain was taken from all subjects with a positive o? LED, or with symptoms of dysuria or urethralo discharge. Between 1 and $2 \%$ of men in each group were found to have gonorrhoea, andô approximately $3 \%$ had urethritis. The majority of cases of urethritis were asymptomatic. $\triangle$ Three percent of women were found to have cervical gonorrhoea on Gram stain, and $2 \%$ serological syphilis (RPR and TPHA+).

The prevalence of STDs found in this refugee population, and the poor correlation between symptoms and confirmed infections, was similar to that found in the rural populare tion of the neighbouring Mwanza region of Tanzania. ${ }^{28}{ }^{29}$ The prevalence of reported life-? time STD symptoms was also similar, with $\frac{0}{0}$ $12 \%$ of women and $13-14 \%$ of men reporting ever having had a genital discharge. The extremely high prevalence of current symp- $\frac{\varrho}{\sigma}$ toms among men may be due in part to poor genital hygiene in the camps (balanitis was fre-o응 quently observed on examination), or may result from the extreme psychological stress endured by these men.

HIV serology was not performed in this study, because of the great political sensitivity of this subject, particularly where refugees are concerned. Although the prevalence of treatable STDs was similar among refugees and the 
surrounding population, large movements of people such as the Rwandan exodus may have important implications for antimicrobial sensitivity patterns of sexually transmitted pathogens. In particular, quinolone resistant strains of Neisseria gonorrhoeae, which have not been previously reported in Tanzania, ${ }^{31}$ are prevalent in Rwanda. ${ }^{32}$

\section{STD control in mobile populations}

The control of STDs in mobile populations such as those described above represents a difficult challenge. Although an improvement in socioeconomic conditions might be the most effective intervention in developing countries, this will be difficult to achieve, and is in the hands of politicians and economists rather than the medical professions for whom this article is intended. Possible biomedical interventions include health education, condom promotion, provision of improved services for STD treatment and STD screening and treatment programmes, for example among antenatal clinic attenders.

Health education can be effective in travellers from developed countries. This was convincingly demonstrated by the educational campaign conducted by the American Peace Corps. ${ }^{33}$ Volunteers (338) who served in Zaire between 1985 and 1988 were enrolled in the study. All received a period of intensive training and counselling before being posted, and no seroconversions to HIV or hepatitis B were observed after a total of 7776 person-months of service. During the study period the incidence of STDs among Peace Corps volunteers in Africa fell from 131 to 68 per 1000 study population per year.

In migrant populations in Africa health education alone may be less effective. For example, it is not helpful to tell the prostitutes in Abidjan described above that their lifestyle is injurious to their health, since many of them know this already, but have no other means of survival. In marginalised groups such as prostitutes and refugees, who often have no access to effective treatment for STDs, provision of such services should be the main priority; simple syndromic management, provided through rural health centres and dispensaries, has been shown to reduce HIV incidence significantly in Tanzania. ${ }^{25}$ However, good curative services alone will not control the AIDS epidemic. Many mine hospitals in South Africa provide excellent STD treatment, but do not attempt to treat contacts, to educate miners about safe sex or to provide condoms; as a consequence, the HIV epidemic continues unabated.

Attempts to control AIDS through the deportation of foreign migrants are doomed to failure, particularly in Africa, where international borders offer little obstacle to would-be immigrants. This strategy was attempted by the mining industry in South Africa in 1987, when all Malawian miners were expelled. ${ }^{18}$ Its futility has been clearly demonstrated by the explosive epidemic which has occurred subsequently. The compulsory testing of travellers, immigrants and migrant workers for HIV infection, although widely practised in many countries, is also doomed to failure in the long term; resources spent on this would be better used for health education and the provision of STD treatment services.

Although difficult, the control of STD/HIV in migrant populations should be a high priority for Ministries of Health in every country, since migrants play a major role in fuelling the HIV/AIDS epidemic. Every means available should be used, including health education, condom promotion and the provision of effective treatment services for STDs which are accessible to marginalised groups such as foreign immigrants.

1 Quetel C. Le Mal de Naples: Histoire de la Syphilis. Paris: Editions Seghers, 1986.

2 International passenger survey 1993. Office of Population and Census, London.

3 Gilmore N, Orkin AJ, Duckett $M$, Grover SA. International travel and AIDS. AIDS 1989;3(suppl 1): S225-30.

4 De Schryver A, Meheus A. International travel and sexually transmitted diseases. Wld Hlth Statist Quart 1989;42: 90-9.

5 Anonymous. AIDS and HIV-1 infection in the United Kingdom. Communicable Disease Report 1994;4:33-4.

6 Anonymous. AIDS and HIV-1 infection in the United Kingdom. Communicable Disease Report 1994;4:51-2.

7 Medical Research Council (UK) Centres for coordinating epidemiological studies of AIDS and HIV infection. Unlinked anonymous monitoring of HIV prevalence in England and Wales: 1990-92. Communicable Disease Report 1993;3:R1-11.

8 Hawkes S, Hart GJ, Johnson AM, Shergold C, Ross E, Herbert KM, et al. Risk behaviour and HIV prevalence in international travellers. AIDS 1994;8:247-52.

9 Bonneux L, Van der Stuyft P, Taelman H, Cornet P, Goilav C, van der Groen C, et al. Risk factors for infection with human immunodeficiency virus among European expatriates in Africa. BMF 1988;297:581-4.

10 Houweling $\mathrm{H}$, Coutinho RA. Risk of HIV infection among Dutch expatriates in sub-Saharan Africa. Int $\mathcal{F} S T D$ and AIDS 1991;2:252-7.

11 Gillies P, Slack R, Stoddart N, Conway S. HIV-related risk behaviour in UK holiday makers. AIDS 1992;6:339-42.

12 Mendelsohn R, Astle L, Mann M, Shahmanesh M. Sexual behaviour in travellers abroad attending an inner-city genitourinary medicine clinic. Genitourin Med 1996;72: genito $43-6$.

13 Daniels DG, Kell P, Nelson MR, Barton SE. Sexual behaviour amongst travellers: a study of genitourinary medicine clinic attenders. Int 7 STD $\mathcal{E}$ AIDS 1992;3:437-8.

14 Nunn AJ, Wagner HU, Kamali A, Kengeya-Kayondo JF, Mulder DW. Migration and HIV-1 prevalence in a rural Ugandan population. AIDS 1995;9:503-6.

15 Kane F, Alary M, Ndoye I, Coll AM, M'boup S, Gueye A, et al. Temporary expatriation is related to HIV-1 infection in rural Senegal. AIDS 1993;7:1261-5.

16 Johnson AM, Wadsworth J, Wellings K, Field J. Sexual Attitudes and Lifestyles. Oxford: Blackwell Scientific, 1993.

17 Decosas J, Kane F, Anarfi JK, Sodji KDR, Wagner HU. Migration and AIDS. Lancet 1995;346:826-8.

18 Jochelson K, Mothibeli M, Leger J-P. Human immunodeficiency virus and migrant labor in South Africa. Intern $\mathcal{F}$ Health Services 1991;21:167-73.

19 Kark SL. The social pathology of syphilis in Africans. $S$ Afr Med F 1949;23:77-84.

20 Delport SD, Rothberg AD. Congenital syphilis-now a notifiable disease. $S$ Afr Med $¥$ 1992;81:288-9.

21 Williams B, Campbell C. AIDS research in Africa: What is to be done? Epidemiology Research Unit Report Series 24. ERU, South Africa, 1994.

22 Dangor Y, Fehler G, Exposto F, Koornhof HJ. Causes and treatment of sexually acquired genital ulceration in southern Africa. $S$ Afr Med $\mathcal{F}$ 1989;76:339-41.

23 Rwanda HIV seroprevalence study group. Nationwide community-based serological survey of HIV-1 and other human retrovirus infections in a central African country. Lancet 1989;i:941-4.

24 Killewo JZ, Sandstrom A, Bredberg-Raden U, Mhalu FS, Biberfeld G, Wall S. Incidence of HIV-1 infection among adults in the Kagera Region of Tanzania. Int $₹$ Epidemiol adults in the Kage
$1993 ; 22: 528-36$.

25 Grosskurth H, Mosha F, Todd J, Mwijarubi E, Klokke A, Senkoro K, et al. Impact of improved treatment of sexually transmitted diseases on HIV infection in rural Tanzania: randomised controlled trial. Lancet 1995;346:530-6.

26 Porter JDH, Van Loock FL, Devaux A. Evaluation of two Kurdish refugee camps in Iran, May 1991: The value of cluster sampling in producing priorities and policy. Disasters 1993;17:341-7.

27 Roseberry WL, Heymann DL, Ndoye I, Nsubuga P. Rapid sexually transmitted diseases assessment in two developing countries. Sex Trans Dis 1994;21;Suppl 2:S84-S85.

28 Grosskurth H, Mayaud P, Mosha FF, Todd J, Senkoro K, 
Newell J, et al. High prevalence of asymptomatic gonorrhea and chlamydial infection in rural Tanzanian men

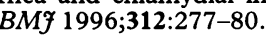

29 Mayaud P, Msuya W, Todd J, Kaatano G, West B, Begkoyan G, et al. STD rapid assessment in Rwandan refugee camps in Tanzania. Genitourin Med 1977;73:33-8.

30 Mayaud P, Grosskurth $\mathrm{H}$, Changalucha J, Todd J, West B, Gabone R, et al. Approaches to the identification of gonorrhea and chlamydial infection in rural Tanzania ANC attenders: risk-assessment and other screening options. Bull WHO 1995;73:621-30.

31 West B, Changalucha J, Grosskurth H, Mayaud P, Gabone $\mathrm{R}$, Ka-Gina $\mathrm{G}$, et al. Antimicrobial susceptibility, auxo- type and plasmid content of Neisseria gonorrhoeae in Northern Tanzania: emergence of high level plasmid mediated tetracycline resistance. Genitourin Med 1995 71:9-12.

32 Bogaerts J, Martinez Tello W, Akingeneye J, Mukantabana $V$ Van Dyck $E$, Piot P. Effectiveness of norfloxacin and ofloxacin for treatment of gonorrhoe vitro sus for treatment of gonorrhoea and decrease of in vitro susceptibility to quinolones

33 Cappello M, Bernard KW, Jones B, Francis H, van der Vlugt $T$. Human immunodeficiency virus infection among peace corps volunteers in Zaire. Arch Intern Med 1991;151:1328-30. 